DOE/me/26253-TII

\title{
SCALE-UP OF MISCIBLE FLOOD PROCESSES
}

DOE/MC/26253-.-MII

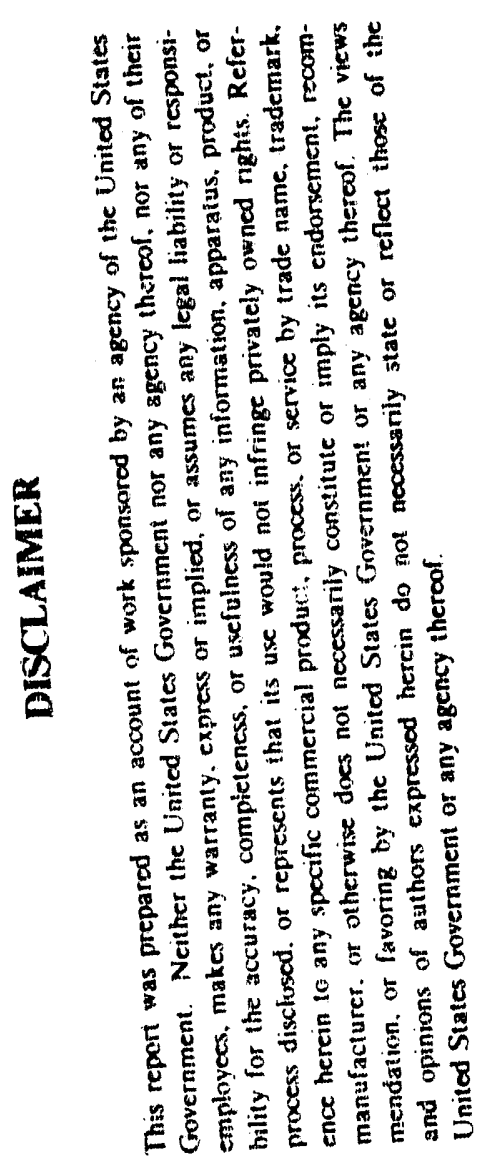

DE92 017668

\author{
Contract No. DE-FG21-89MC26253
}

Department of Petroleum Engineering

Stanford University

Stanford, CA 94305

Principal Investigator: Franklin M. Orr, Jr.

Project Manager: Royal Watts

Morgantown Energy Technology Center

Reporting Period: January' 1 - April 31, 1992

MATRR

$w^{0}(3)$

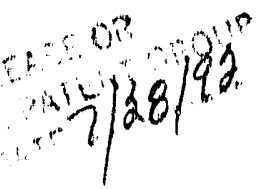




\section{Introduction}

Miscible flooding processes have generally been applied in reservoirs that are not too heterogeneous. The low viscosity of the injected gas insures that it will flow rapidly in high permeability zones or fractures. The worry is that highly heterogeneous or fractured reservoirs may experience early breakthrough of injected fluid, poor sweep efficiency, and extensive 'ycling of injected fluid. Much of the current DOE supported research program is aimed at providing much better description of the heterogeneities $p_{i}$ esent in various classes of reservoirs. That research effort is based on the iden that heterogeneity dominates flow in most reservoirs.

Efficient application of miscible floods to heterogeneous reservoirs requires the designer to take advantage of more than one of the physical mechanisms that act and interact to determine displacement performance. In this report, we summarize the interactions of phase behavior, nonuniform flow, and crossflow and based on novel results obtained during the course of our experimental efforts, we suggest design opportunities for application of gas injection to near-miscible recovery processes, to enhanced gravity drainage, and even to fractured reservoirs. To design such processes intelligently, the quantitative scaling of the interplay of phase equilibria, reservoir heterogeneity, viscous fingering and particularly crossflow must be understood. In essence, we propose to make use of crossflow, i.e. transport in the direction transverse to the basic flow direction, to sweep portions of reservoirs that can be reached only very slowly by direct displacement.

\section{Project Status}

\section{Low IFT Capillary Imbibition and Gravity Segregation}

Where dispersion is present, as would be the case during a imulticontact miscible flood in a heterogeneous reservoir, the important effect of phase behavior is to force the composition path to traverse a tie line that is nearly critical. The equilibrium phases associated with that tie line will have compositions that are nearly the same, and as a result will have relatively low interfacial tensions (IFT"s). Those low IFT"s, in turn, make enhanced crossflow possible, as the discussion that follows will demonstrate. 
Table 1: Phase Properties for Three Equilibrium Tie-Lines

\begin{tabular}{|c|c|c|c|}
\hline Tie Line & $\Delta \rho\left(\mathrm{g} / \mathrm{cm}^{3}\right)$ & IFT $(\mathrm{mN} / \mathrm{m})$ & Viscosity Ratio $\left(\mu_{w} / \mu_{0}\right)$ \\
\hline 1 & 0.33 & 38.1 & 2.0 \\
2 & 0.21 & 1.07 & 6.25 \\
3 & 0.11 & 0.10 & 3.71 \\
\hline
\end{tabular}

If two phases are present in essentially all MCM floods, then both capillary and gravity forces will contribute to the movement of fluids between zones of high and low permeability. Capillary imbibition will move wetting phase into zones of low wetting-phase saturation or lower permeability, and density differences between phases will cause the less dense phase to move upward and/or the more dense phase to move downwards.

\section{Results}

Experimental investigation in our laboratory of the interplay of gravity and capillary forces has demonstrated that when the IFT is moderately low, gravity segregation gives rise to rapid and efficient recovery during both the imbibition and drainage process $[9,7]$. Cylindrical cores about $60 \mathrm{~cm}$ in length and $6.35 \mathrm{~cm}$ in diameter were mounted vertically in a plexiglass holder. In a typical experiment, the core was saturated with oil, and then it was rapidly immersed in water. The less dense oil phase was then produced by a combination of gravity segregation and capillary imbibition. (More detailed descriptions of the experimental work and results are given in references [9] and [i]).

To investigate how oil recovery changes with IFT, experiments were performed with the mixtures of isooctane $\left(I C_{8}\right)$, brine $\left(2 \mathrm{wt} . \% \mathrm{CaCl}_{2}\right)$ and isopropanoi (IPA). The imbibition experiments were performed with equilibrated fluids on three tie lines shown in Fig. 1. Properties of the phases are summarized in Table 1. As Table 1 and Fig. 1 show, as $I P A$ is added, the IFT is reduced. On tie line 1 in Fig. 1, for example, the brine and $I C 8$ with no IPA have an IFT of $38 \mathrm{mN} / \mathrm{m}$ and a density difference of $0.33 \mathrm{~g} / \mathrm{cm}^{3}$, while tie line 3 exhibits an IFT two orders of magnitude lower with a density difference that is three times lower. 


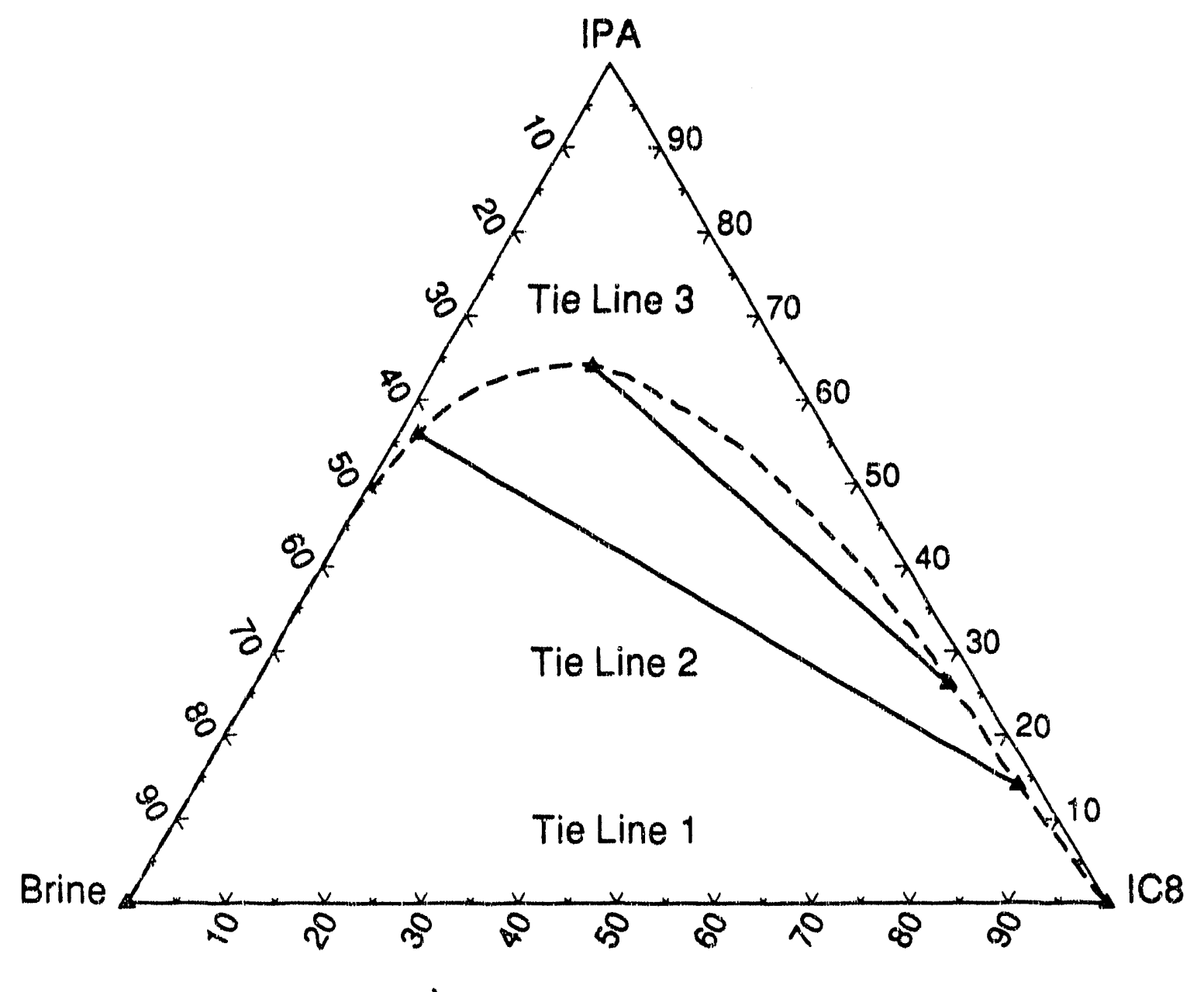

Figure 1: Phase diagram for $I C 8, I P A$ and brine system 
Results of experiments in a Berea sandstone core with a permeability of $100 \mathrm{md}$ are shown in Fig. 2. Despite the fact that both the capillary and density driving forces decreased as the IFT was reduced, the total recovery and the rate both increased. (For additional experimental results that show similar behavior, see Schechter et al. $[9,7])$.

The experimental results in Fig. 2 indicate that relatively rapid and high recovery is possible even when the IFT is only moderately low. As the IFT is reduced gravity forces become more important relative to the capillary forces $[9,7]$. It is important to recognize that when capillary pressure is diminished, both the wetting and nonwetting phases segregate by gravity, which can lead to efficient production rates and high final recoveries. Fig. 3 shows, for example, that when the equilibrated fluids of tie line 3 were used, the wetting brine phase initially present in the core could be removed by gravity drainage just as oil phase could by gravity imbibition. Presumably, the imbibition and drainage curve would be the same at neutral wetting conditions or negliole capillary pressure. Obviously, capillary pressure is important even at this low value of IFT as is evidenced by the longer time required for drainage. The drainage mechanism is still quite effective at low IFT with a hydrostatic pressure in the fracture capable of overcoming the threshold capillary pressure required to initiate drainage. Also shown is the same drainage experiment performed with the lateral face open and wrapped in teflon. In contrast with imbibition, where the rate is proportional to the surface area available for imbitition, covering the lateral face caused faster drainage with better recoveries. This suggests that nonwetting phase was pentrating the lateral face and interfering with the downward gravity stabilized front. Such interference is responsible, in turn, for the lower recoveries observed during open face drainage.

Thus, if IFT is moderately low, gravity forces can move substantial quantities of both wetting and nonwetting phases at significant rates. In multicontact miscible flood processes, the effects of equilibrium partitioning of components between phases can easily produce IFT's in the range where enhanced gravity-driven crossflow is possible.

\section{Discussion}

Even though the experiments outlined were performed with analog fluids, they indicate that similar behavior will be quite important in $M C M$ dis- 


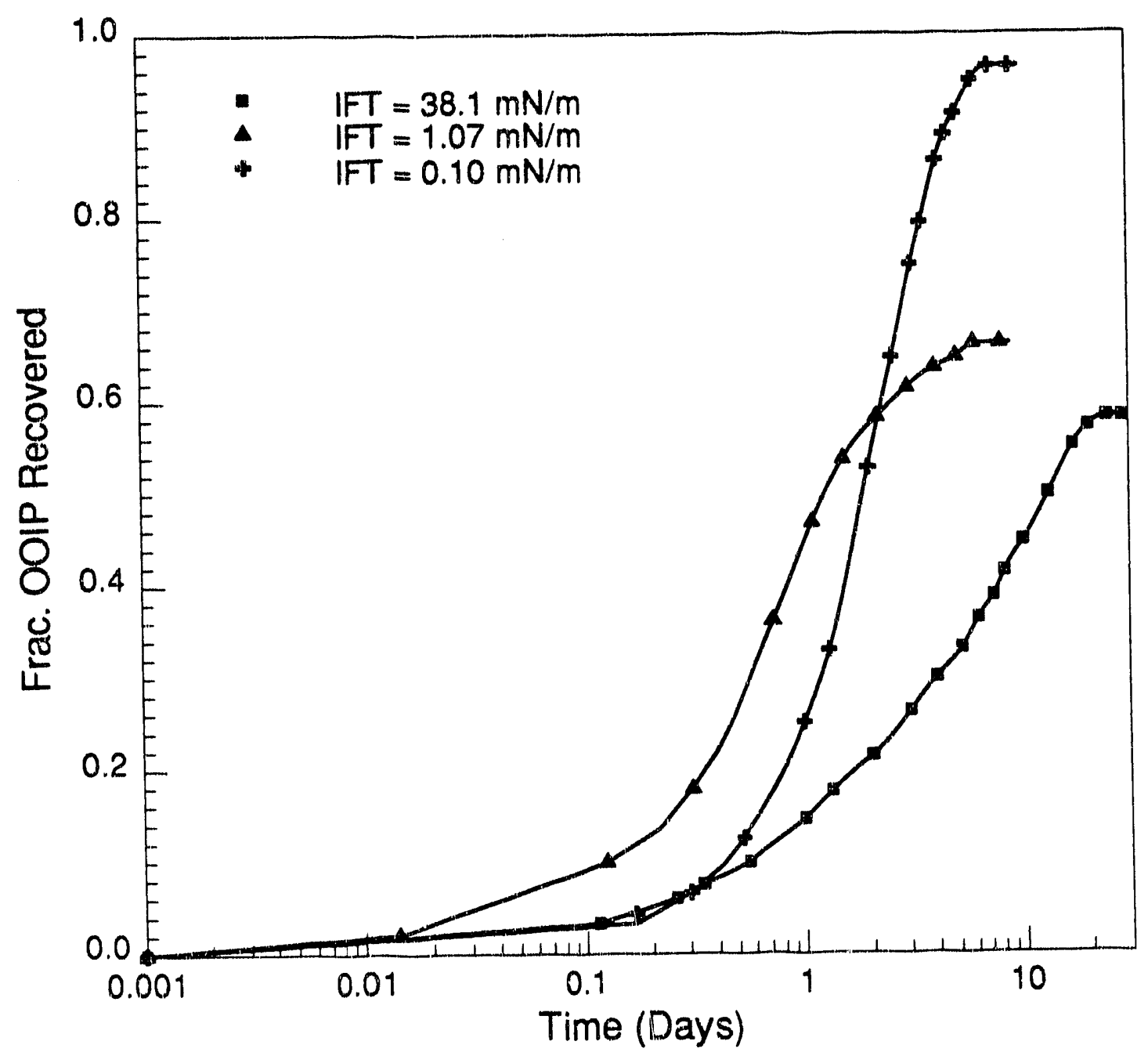

Figure 2: Recovery curve for $100 \mathrm{md}$ Berea at three different IFT's 


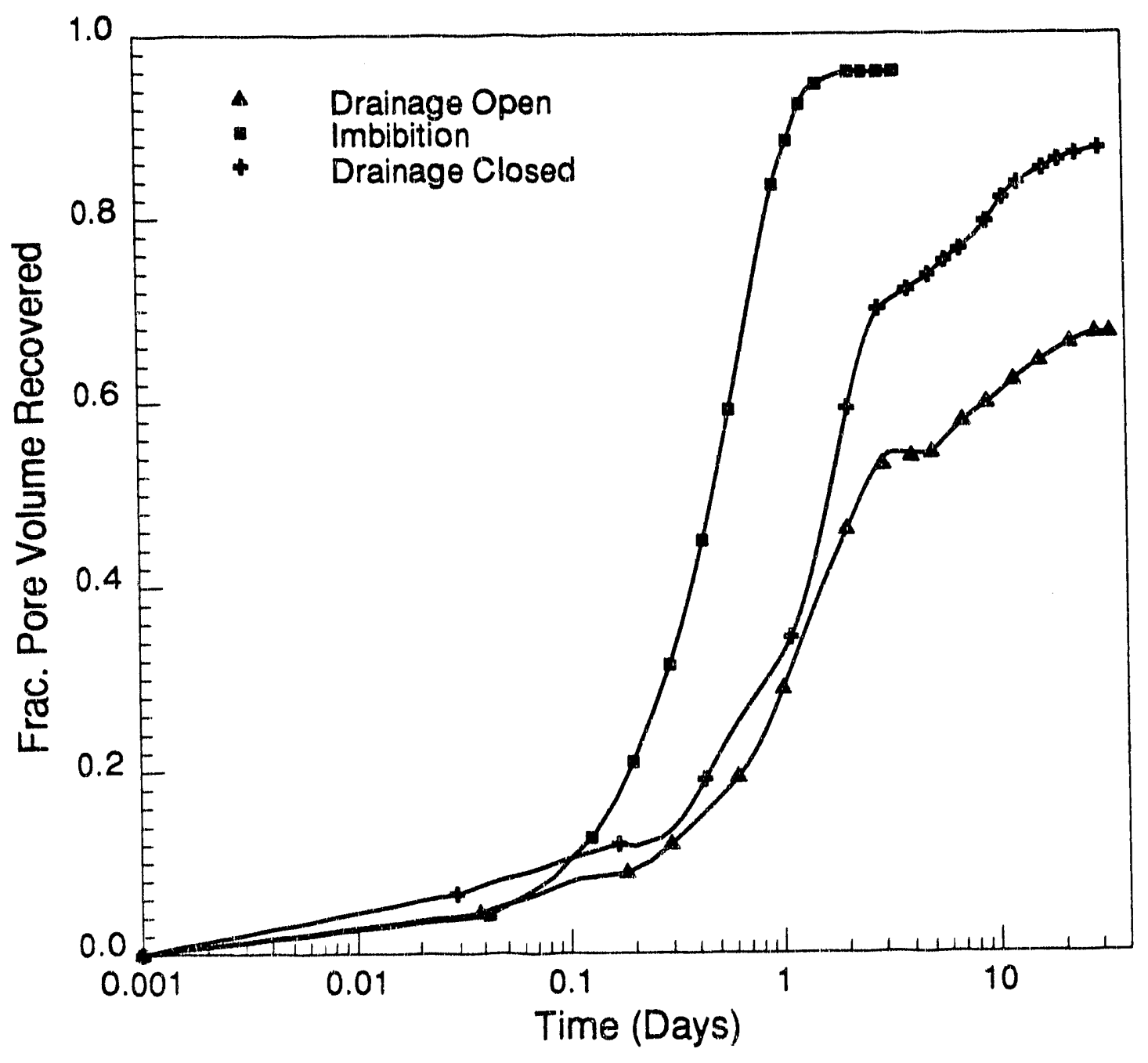

Figure 3: Spontaneous drainage of brine, IFT $=0.1 \mathrm{mN} / \mathrm{m}$, from $500 \mathrm{md}$ Berea. 
placement processes in heterogeneous reservoirs. The explanation of this phenomenon comes from the fundamental principles of near-critical phase transitions. An analysis of the scaling behavior of the density difference and IFT of coexisting phases near their critical point of miscibility indicates that as the critical point is approached, IFT decreases more rapidly than density difference [10]. Fig. 4 shows a plot of IFT against density difference between phases for oil-water-alcohol systems $[2,6,8]$. It demonstrates the relationship between density difference and IFT in the near-critical region and also shows the slope of the straight line of 3.8 , which is consistent with critical scaling theory [10].

According to that theory, the same behavior will be observed for gas-oil systems near a critical point. This was verified in measurements by Haniff and Pearce [4] on a gas-condensate mixture near miscibility. The phase equilibrium mechanism of a successful MCM process will generate mixtures that are near a critical point, and hence, there will be regions of the flow where gravity forces will be more important than capillary forces. In these regions, then, gravity-driven crossflow can be used to invade zones not swept by longitudinal flow if adequate vertical communication exists. This argument suggests that a miscible gas injection process could be used effectively in a fractured reservoir.

In fact, a successful field application of $\mathrm{CO}_{2}$ injection in a fractured reservoir was recently reported [1]. The observations reported by Beliveau and Payne are consistent with the mechanisms described here. They described a pilot test currently underway in the Midale field in which $\mathrm{CO}_{2}$ was injected at a pressure above the MMP in a fractured carbonate reservoir. When water was injected in the pilot area, it rapidly broke through to the producing wells, in some cases, in less than one day. When $\mathrm{CO}_{2}$ was injected, however, it broke through much later, a clear indication that $\mathrm{CO}_{2}$ was invading low permeability matrix blocks. Actual oil production in the pilot test indicated that $\mathrm{CO}_{2}$ utilization was only about $3 \mathrm{MCF} / \mathrm{STB}$. At reservoir conditions 1.7 MCF were required to produce a barrel of oil, so the observed $\mathrm{CO}_{2}$ utilization is remarkable. It is much lower than is typical in other miscible flood applications. Hence it is clear that the reasons for success at Midale should be explored in detail so that similar successes can be achieved in other fractured reservoirs.

The objective of a recovery method for fractured reservoirs should be to use the fracture network as a delivery system to carry injected fluid to 


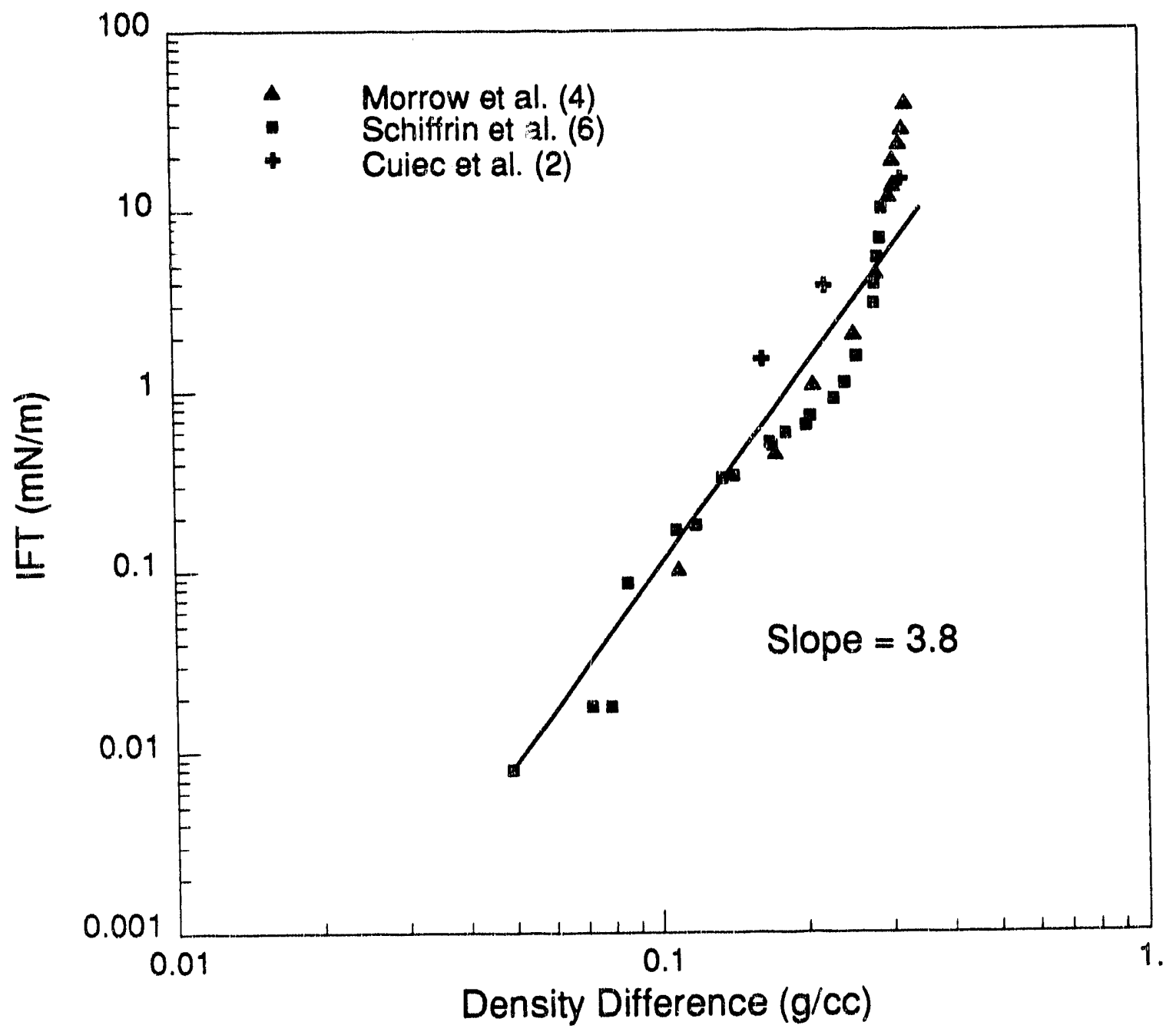

Figure 4: IFT vs. density difference for phases approaching miscibility 
the matrix regions to be swept and to move oil recovered from the matrix to production wells by gravity drainage. If a MCM gas is injected into a vertically fractured network, the gas will rise through the highly permeable fracture paths. The combination of the hydrostatic pressure and reduced IFT's as the gas becomes miscible with the oil in the matrix will allow gravity drainage to become an extremely effective recovery mechanism as has been shown in the fractured Midale system [1].

\section{Flow Visualization Experiments}

Visualization experiments have been performed by Zhou [7] in which cross-

flow was experimentally examined in a layered bead pack. First contact miscible displacements were carried out by injecting $I C 8$ into a two layer pack saturated with IPA. The direction of crossflow was found to be dependent on the rate of injection. At low flow rates $(0.5 \mathrm{ml} / \mathrm{min}), I P A$ crossflow occurred from the top layer to the bottom layer as shown in Fig. 5; while IC 8 was observed to move from the lower to upper layer at higher flow rate $(1.0 \mathrm{ml} / \mathrm{min})$ as demonstrated in Fig. 6 . In both cases, sweep efficiency was significantly improved compared with the no crossflow situation. These visualization experiments demonstrate that viscous and gravity-driven crossflow play an important role in improving the sweep efficiency of stratified systems if the process is engineered correctly.

Real miscible floods will be more complex still because crossflow and its interactions with phase behavior will induce IFT gradients. Additional experiments reported by Schechter et al. [9] indicate that IFT gradients can help or hinder crossfiow significantly, depending on whether the direction of the gradient aids or impedes the flow. Thus one objective of design of processes that make use of crossflow should be to take advantage of IFT gradients. Consider a fractured reservoir, for example. If relatively low IFT's can be created inside a matrix block, as would happen as $\mathrm{CO}_{2}$ at a pressure above the MMP invaded the block, then higher IFT's at the edge of the block would cause faster flow of oil phase toward the fracture [9]. To design such a process, the details of the interaction of cross flow with phase equilibrium must be worked out. 


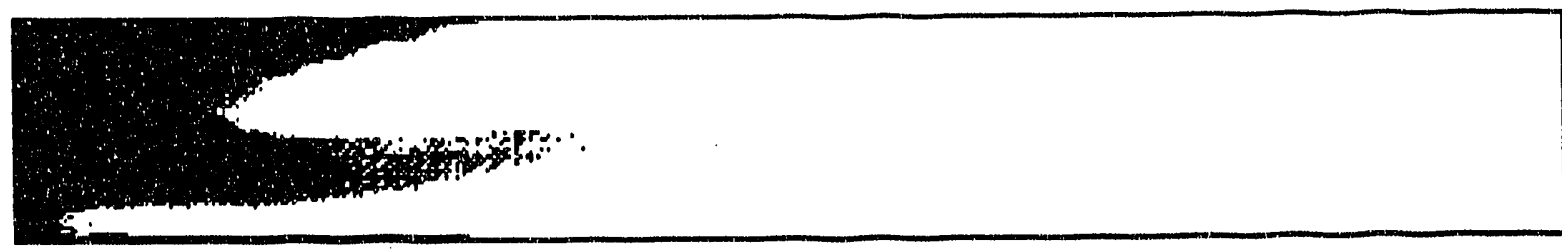

$$
P V \mid=0.10
$$

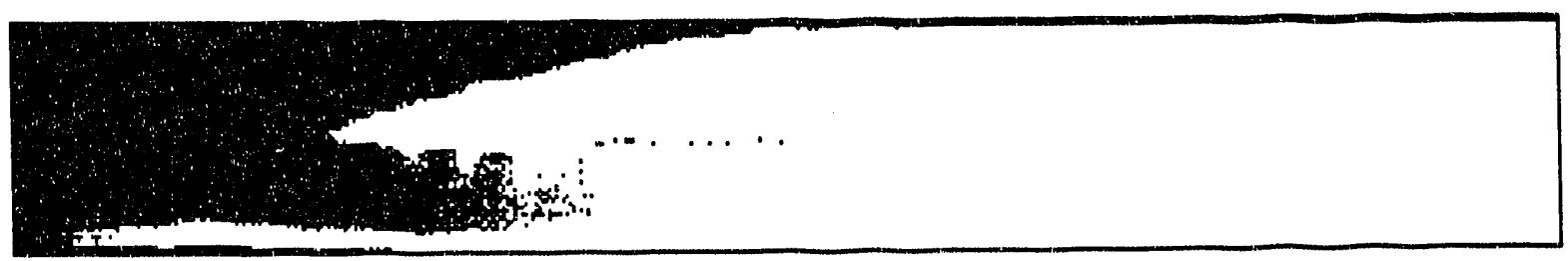

$$
P Y \mid=0.20
$$

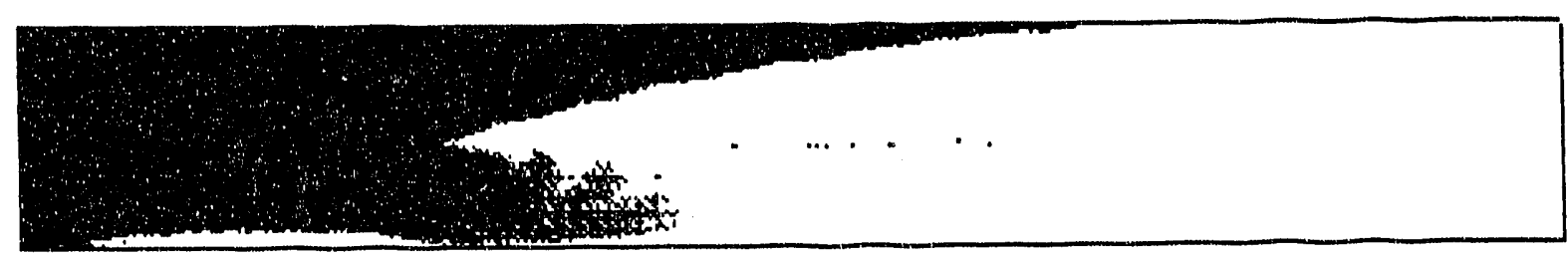

$$
P Y \mid=0.30
$$

Figure 5: Viscous and gravity-driven crossflow at flow rate $=0.5 \mathrm{ml} / \mathrm{min}$. 


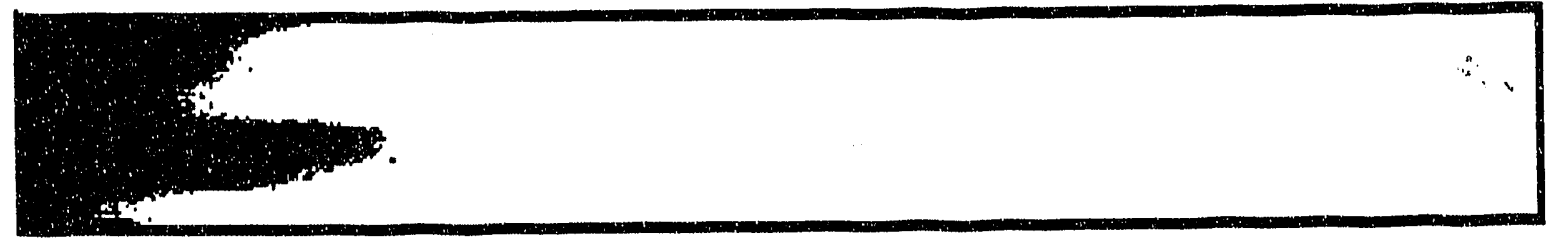

$$
\mathrm{PY} \mid=0.10
$$

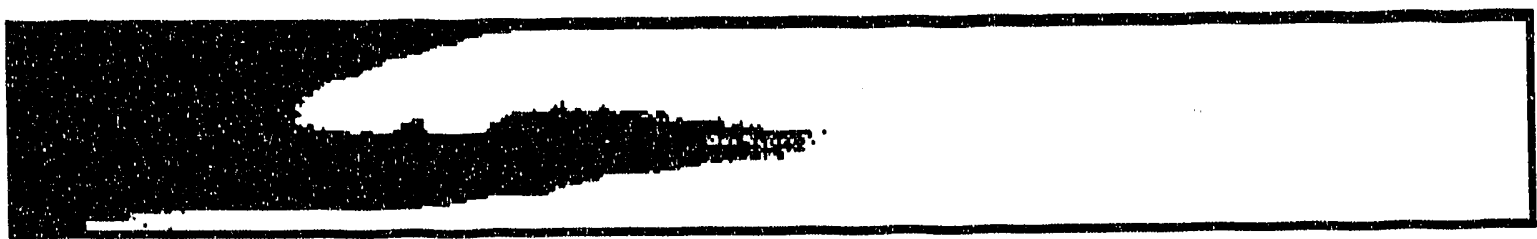

$P V \mid=0.20$

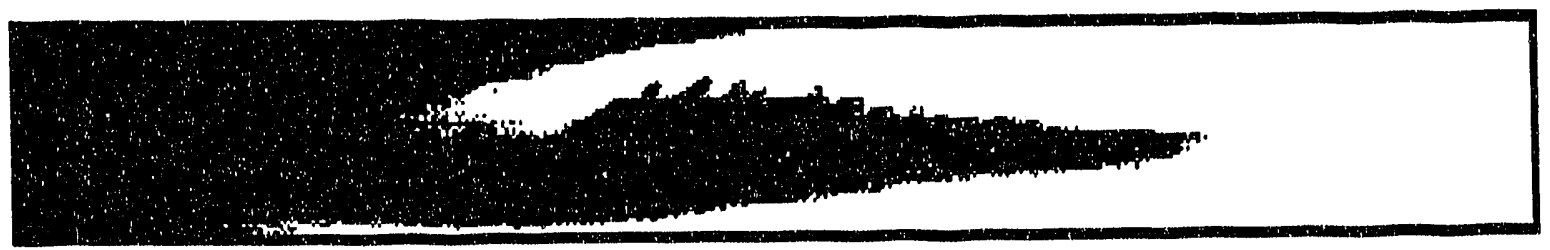

$$
P V \mid=0.30
$$

Figure 6: Viscous and gravity-driven crossflow at flow rate $=4.0 \mathrm{ml} / \mathrm{min}$. 


\section{Summary}

The core displacement and flow visualization experiments described here suggest that the effects of low IFT's and gravity can be used to advantage in the

design of multicontact miscible displacements for heterogeneous reservoirs, including fractured reservoirs. 


\section{References}

[1] Beliveau, D. and Payne, D.A.: "Analysis of a Tertiary $\mathrm{CO}_{2}$ Flood Pilot in a Naturally Fractured Reservoir," paper SPE 22947 presented at the 1991 Annual Technical Conference, Dallas, TX, Oct. 6-9.

[2] Cuiec, L.E., Bourbiaux, B. and Kalaydjian, F.: "Imbibition in LowPermeability Porous Media: Understanding and Improvement of Oil Recovery,", paper SPE 20259 presented at 1990 7th Annual Symposium on Enhanced Oil Recovery, Tulsa, OK, April.

[3] Haniff, M.S. and Pearce, A.J.: "Measuring Interfacial Tensions in a GasCondensate System with a Laser-Light-Scattering Technique," SPERE, Pg. 589-594, Nov. 1990.

[4] Morrow, N.R., Chatzis, I. and Taber, J.J.: "Entrapment and Mobilization of Residual Oil in Bead Packs", Soc. Pet. Eng. Res. Eng., 3, $927-935,1988$.

[5] Orr, F.M., Jr.: "Scale-Up of Miscible Flood Processes," Annual Report No. U.S. DOE Grant No. DE-FG21-89MC26253, U.S. Department of Energy, Bartlesville, OK (1991).

[6] Satherly, J. and Schiffrin, D.J.: "The Measurement of Low IFT Values for Enhanced Oil Recovery", Progress Report to U.K. DOE, Winfrith, August, 1986.

[7] Schechter, D.S., Zhou, D. and Orr, F.M., Jr.: "Capillary Imbibition and Gravity Segregation in Low IFT Systems," paper SPE 22594 prese..ted at the 1991 SPE Annual Technical Conference and Exhibition, Dallas, TX, October 6-9.

[8] Shang-keng, M.: Modern Theory of Critical Phenomena, Benjamin Cummings, Reading, Mass. (1976). 
$\rightarrow$
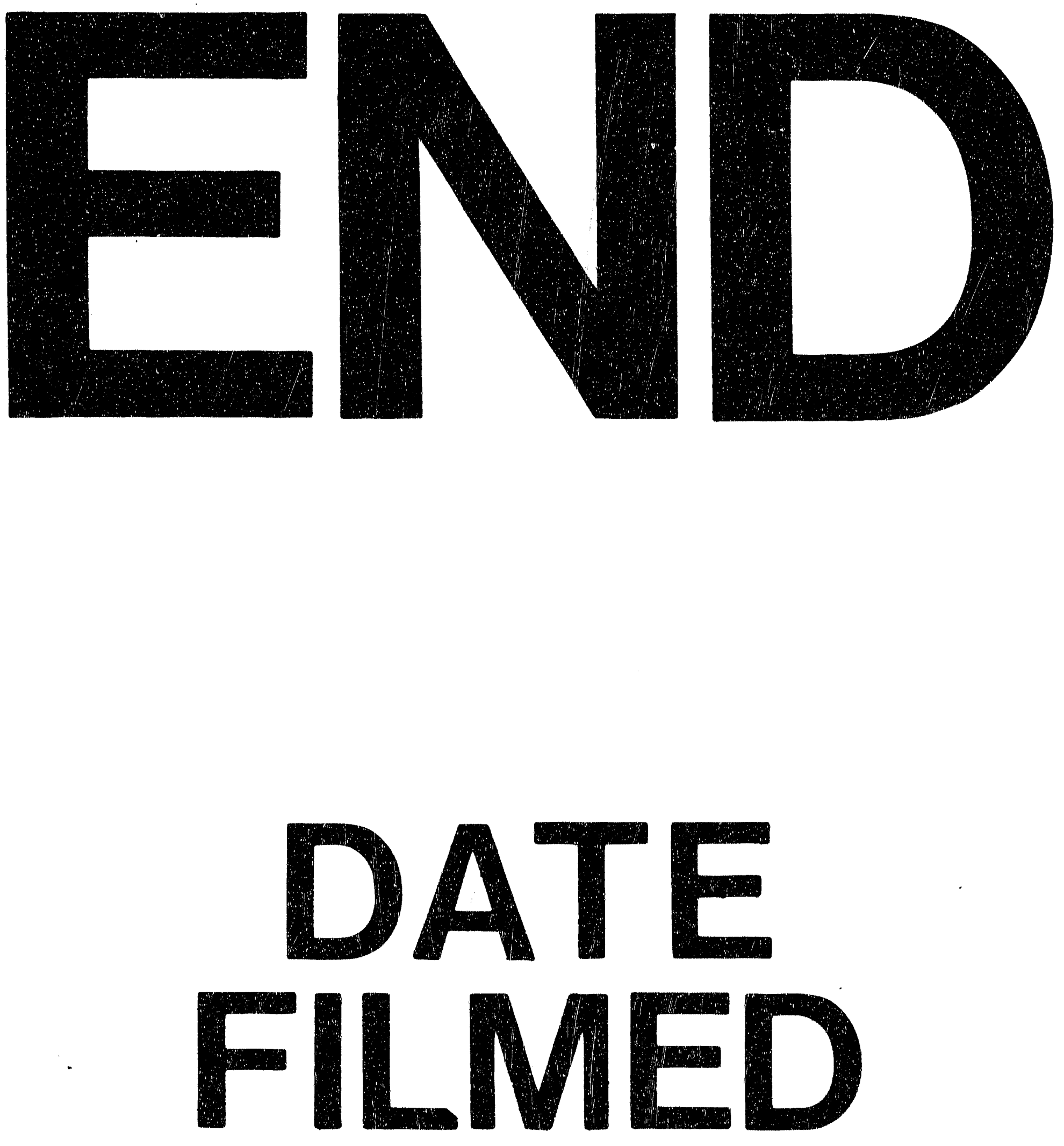

書

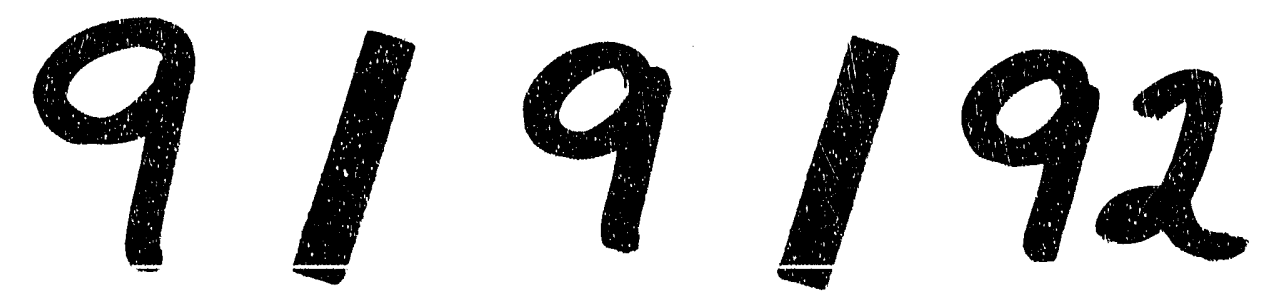


